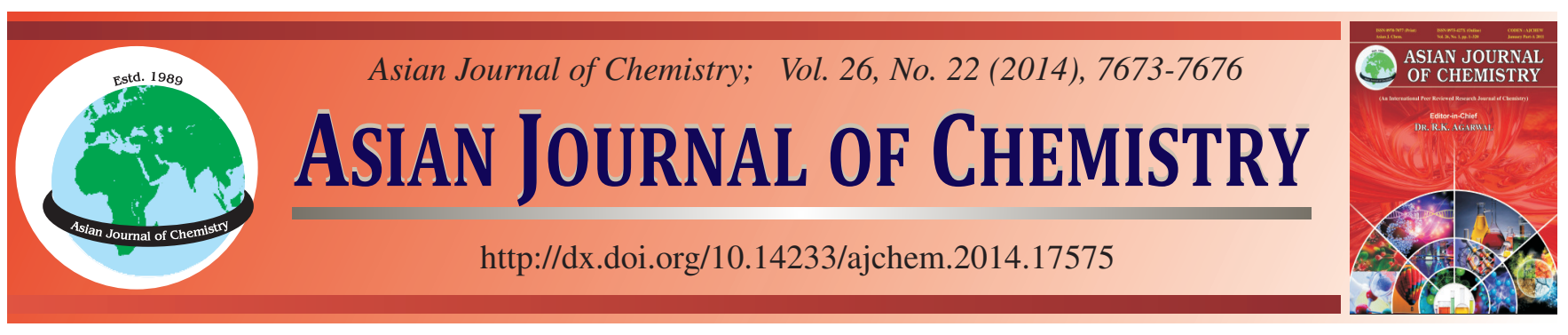

\title{
Simultaneous Quantification of Quercetin, Myricetin and Kaempferol in Extracts and Latex of Euphorbia helioscopia Using RP-HPLC
}

\section{Uzma SAleEm $^{1,2}$, Bashir Ahmad $^{3, *}$, Khalid Hussain $^{1}$, Mobasher Ahmad $^{1}$ and Nadeem Irfan Bukhari ${ }^{1}$}

${ }^{1}$ University College of Pharmacy, University of the Punjab, Lahore, Pakistan ${ }^{2}$ College of Pharmacy, Government College University, Faisalabad, Pakistan

${ }^{3}$ School of Pharmacy, University of South Asia, Lahore, Pakistan

*Corresponding author: E-mail: ahmadbprof@gmail.com

\begin{abstract}
Herbal products are consistently inconsistent due to a number of factors and their standardization is tedious task, and considering its importance, the present study aims to develop and validate an easy method for the standardization of extracts/products prepared from Euphorbia helioscopia (Family: Euphobiaceae) which is a traditional medicinal plant. Three pharmacologically active compounds such as quercetin, myricetin and kaempferol were used as analytical markers to develop and validate a reversed-phase HPLC method. The standards were eluted through column (Eclipse XDB-C18, $5 \mu \mathrm{m}, 4.6 \times 150 \mathrm{~mm}$ ) using isocratic mobile phase comprising methanol and $0.2 \%$ phosphoric acid $(65: 35, \mathrm{v} / \mathrm{v})$. The flow rate was kept at $1 \mathrm{~mL} / \mathrm{min}$, temperature of the column was maintained at $30^{\circ} \mathrm{C}$ and detection was carried out at $360 \mathrm{~nm}$. The method was found to be linear for all the three standards in the whole range investigated $\left(\mathrm{R}^{2}=0.982\right.$ to 0.998). The limit of detection (LOD) and limit of quantification (LOQ) for quercetin and myricetin were 0.04 and $0.15 \mu \mathrm{g} / \mathrm{mL}$, respectively, and kaempferol 0.54 and $1.81 \mu \mathrm{g} / \mathrm{mL}$. The method showed repeatability and reproducibility with RSD $<5 \%$. The method was successfully applied to different types of extracts of the plant. Therefore, it is concluded from the study that the method is simple, linear, selective, repeatable and reproducible. Moreover, the method can be applied for the standardization of extracts/exudates of the plant.
\end{abstract}

Keywords: RP-HPLC, Quercetin, Myricetin, Kaempferol, Euphorbia helioscopia.

\section{INTRODUCTION}

Euphorbia helioscopia (Family: Euphorbiaceae) is a traditional medicinal plant found in many countries. As a folk remedy, it is used as anthelmintic, vermifuge and febrifuge, and to treat cholera and constipation ${ }^{1-4}$. The plant has also been investigated for a number of pharmacological activities such as antifungal, antibacterial, antiviral, phytotoxicity, vasodepressor, anticancer, antioxidant, molluscicidal and anti-asthmatic ${ }^{5-13}$. This interest of scientists shows the medicinal and commercial importance of the plant. For such purposes, there is a need of development of analytical methods which can be used to standardize products prepared from extracts of the plant.

The plant is reported to have a diverse type of chemical compounds such as triterpenoids ${ }^{14}$, diterpenoids ${ }^{15-18}$, flavonoids ${ }^{19,20}$, tannins and lipids ${ }^{17}$. Zhang and $\mathrm{GuO}^{21}$ have identified 24 metabolites belonging to different chemical groups. Eight different categories of chemical compounds are suggested to be used as analytical standards ${ }^{22}$. In the present study, we have selected three pharmacologically active flavonoids such as quercetin, myrecetin and kaempferol to be used as analytical standards for the development of HPLC method that can be used for standardization purposes.
The development of methods for the simultaneous quantification is considered better than that of the single standard methods. In such methods, many compounds can be quantified in samples in lesser time using small quantity of solvents. Keeping it in view, the present study was undertaken to develop, validate and apply a simultaneous HPLC method using three standards.

\section{EXPERIMENTAL}

The chemicals used in the study included petroleum ether (Analytical grade; Sigma Aldrich), ethanol (Analytical grade; BDH Laboratory), chloroform and methanol (Analytical grade; Merck, Germany), methanol (HPLC grade, RCI Labscan Ltd.), phosphoric acid, quercetin (Merck Germany), myrecetin and kaempferol (MP Biomedicals, LLC., France) were procured from local market.

High performance liquid chromatography (HPLC)system, 1200 series (Agilent Technologies, Waldronn, Germany) equipped with auto sampler, type G1329A, column heater,type G1316A, isocratic pump type, G1310A, DAD, type G1315B and florescent light detector, type G1321 A was used. The data acquisition was performed using software, ChemStation, version A. 08.03. 
Collection of plant material: The plant Euphorbia helioscopia was collected from suburbs of Lahore-Pakistan. After identification and authentication by a Taxonomist of Botany Department, Government College University (GCU) Lahore-Pakistan, a voucher specimen (1501) was deposited to their herbarium. Leaves and stem were separated and dried under shade. They were ground to fine powder separately which were then used in extraction. The latex was collected in dried bottles by cutting the leafy part from the stem.

Preparation of extract: The pulverized material from both of the parts of the plant was extracted separately at ambient temperature by maceration in water and ethanol as solvents. Then both the materials were extracted sequentially using solvents in the order of increasing polarity by soxhlet apparatus. The solvent was removed from the extracts on rotary evaporator at $40{ }^{\circ} \mathrm{C}$.

UV and FTIR finger prints of all the extracts of leaves and stem showed overlapping behaviour in earlier research ${ }^{23}$, keeping in view this result, only leaves extracts were selected for the current study.

Chromatographic conditions: The mobile phase was filtered through $0.45 \mu \mathrm{m}$ nylon membrane filter and degassed by placing it in sonicator. Separation was carried out with Eclipse XDB-C18 $(5 \mu \mathrm{m}, 4.6 \times 150 \mathrm{~mm})$ using isocratic mobile phase comprising methanol: $0.2 \%$ phosphoric acid (65: 35 , $\mathrm{v} / \mathrm{v}$ ) at flow rate of $1 \mathrm{~mL} / \mathrm{min}$ and $30{ }^{\circ} \mathrm{C}$ temperature. The injection volume was $20 \mu \mathrm{L}$. DAD detector was operated at $360 \mathrm{~nm}$.

Preparation of standard solutions: The stock solutions of quercetin, myricetin and kaempferol having concentration $1 \mathrm{mg} / \mathrm{mL}$ were prepared in HPLC grade methanol. A mixed standard stock solution was prepared by mixing $50 \mu \mathrm{g} / \mathrm{mL}$ of quercetinand kaempferol, and $100 \mu \mathrm{g} / \mathrm{mL}$ of myrecetin. Then a series of mixed working standard solutions were prepared containing quercetin $(2.5,5,7.5,10$ and $25 \mu \mathrm{g} / \mathrm{mL})$, kaempferol $(10,15,20,50,75 \mu \mathrm{g} / \mathrm{mL})$ and myricetin $(5,10,15,20,50$ $\mu \mathrm{g} / \mathrm{mL}$ ) by diluting the stock solutions with methanol (HPLC grade). All the standard solutions were filtered using $0.45 \mu \mathrm{m}$ polytetrafluoroethylene (PTFE) syringe filters (Whatman, Maidstone, England).

Preparation of samples: The working solutions of all the extracts $(5 \mathrm{mg} / \mathrm{mL})$ were prepared in HPLC grade methanol. The latex was mixed with HPLC grade methanol in 1:1 ratio $(\mathrm{v} / \mathrm{v})$. The sample solutions were filtered like the standards.

Assay validation: Limit of detection (LOD), limit of quantification (LOQ), linearity, inter-day and intra-day accuracy, precision and selectivity parameters were determined for assay validation $^{24,25}$.

Limits of sensitivity: Sensitivity of the instrument was assessed by measuring LOD and LOQ. Limit of detections of quercetin, myricetin and kaempferol were determined at signal to noise $(\mathrm{S} / \mathrm{N})$ ratio 3:1, whereas LOQs were calculated at $\mathrm{S} / \mathrm{N}$ ratio 10:1. Five standard solutions in concentration range of 2.5 to $25 \mu \mathrm{g} / \mathrm{mL}$ (quercetin), 5 to $50 \mu \mathrm{g} / \mathrm{mL}$ (myricetin), and 10 to $75 \mu \mathrm{g} / \mathrm{mL}$ (kaempferol) were analyzed in six replicates. Calibration curves were constructed between concentration $(\mu \mathrm{g} / \mathrm{mL})$ and peak area (mAU) and the linear regression equations obtained were used to determine LOD and LOQ using the following equations:

$$
\begin{aligned}
& \text { LOD }=\frac{[\text { SD intercepts }(n=6)]}{[\text { Slope mean }(n=6)]} \times 3 \\
& \text { LOQ }=\frac{[\text { SD intercepts }(n=6)]}{[\text { Slope mean }(n=6)]} \times 10
\end{aligned}
$$

Linearity: The standard solutions of quercetin, myricetin and kaempferol in concentration range 2.5, 5, 7.5, 10 and 25 $\mu \mathrm{g} / \mathrm{mL}, 5,10,15,20,50 \mu \mathrm{g} / \mathrm{mL}$ and $10,15,20,50,75 \mu \mathrm{g} / \mathrm{mL}$ respectively were analyzed in triplicate. Linearity was observed visually from calibration curves and the correlation of the data points was assessed by correlation coefficient $\left(\mathrm{R}^{2}\right)$.

Precision and accuracy: Percent relative standard deviation (RSD \%) was used to measure inter-day and intra-day precision over the concentration range of calibration curves of all the standards during the time period of validation. The accuracy of the assay was measured in terms of percent recovery; calculated by dividing the concentration found with nominal concentration and multiplied with hundred. Six replicates were used to measure inter-day (six consecutive days) and intraday (six times in the same day) precision and accuracy.

Selectivity: Three quality control samples of quercetin $(2.5,7.5$ and $25 \mu \mathrm{g} / \mathrm{mL})$, myricetin $(5,15$ and $50 \mu \mathrm{g} / \mathrm{mL})$ and kaempferol $(10,20$ and $75 \mu \mathrm{g} / \mathrm{mL})$ were prepared as unknown samples. The concentration in each sample was calculated from calibration curve and compared with that of nominal concentrations. Extraction recovery was executed in three replicates.

Quantification of quercetin, myricetin and kaempferol in samples: The working solutions of extracts were analyzed in triplicate at chromatographic conditions mentioned above. Chromatographic peaks of samples were identified by comparing the retention time with those of markers and finally quantified using the external standard method.

\section{RESULTS AND DISCUSSION}

Chromatography conditions: Development of method was focused on simultaneous quantification of three flavonoids (quercetin, myricetin and kaempferol). A number of mobile phases, varying temperatures and flow rates were tested to optimize the method to get sharp chromatogram with good resolution. Fine separation of flavonoids in samples was achieved with mobile phase: methanol: $0.2 \%$ phosphoric acid (65: $35 ; \mathrm{v} / \mathrm{v}$ ), at temperature $30^{\circ} \mathrm{C}$ and flow rate $1 \mathrm{~mL} / \mathrm{min}$. Quantification was carried out from standard curves of the respective standards.

\section{Method validation}

Limit of detection and limit of quantification: Limit of detection is the lowest concentration of analyte that can be detected above the baseline detector noise at the most sensitive instrument setting, but not necessarily quantified. The LOQ is the minimum injected amount that gives precise measurements, in chromatography typically requiring peak heights 10-20 times higher than baseline noise $\mathrm{e}^{26}$.

Limit of detection for quercetin and myricetin was 0.04 but it is higher for kaempferol i.e. 0.54 and similarly the LOQ for quercetin and myricetin was low $(0.15)$ as compared to kaempferol LOQ i.e. 1.81 (Table-1). 
Linearity: Linearity was determined by series of five concentrations for each standard marker. Calibration curves were linear with correlation coefficients $\mathrm{R}^{2}=0.9971$ (quercetin), $\mathrm{R}^{2}=0.9978$ (kaempferol) and $\mathrm{R}^{2}=0.982$ (myricetin) over the concentration ranges $2.5,5,7.5,10$ and $25 \mu \mathrm{g} / \mathrm{mL}$ (quercetin), 5, 10, 15, 20, 50 $\mu \mathrm{g} / \mathrm{mL}$ (myricetin) and 10, 15, 20, 50, $75 \mu \mathrm{g} / \mathrm{mL}$ (kaempferol) as described in Fig. 1 and Table-1.

Precision and accuracy: Acceptable limit for precision is $2-20 \%$ for environmental samples and for accuracy is \pm $20 \%$. Our results showed good precision and accuracy as described in Table-2 for quercetin, myricetin and kaempferol respectively.
Selectivity: Three quality control samples of each standard marker (quercetin, myricetin and kaempferol) were evaluated and their accuracy and precision were presented in Table-3.

Quantification of quercetin, myricetin and kaempferol in samples: Quercetin, myricetin and kaempferol were quantified in all the extracts and latex. Quercetin contents were found in following descending order: ethanol extract $(5.6 \mathrm{mg} / \mathrm{g})$ $>$ methanol extract $(5.32 \mathrm{mg} / \mathrm{g})>$ latex $(1.40 \mathrm{mg} / \mathrm{g})>$ chloroform extract $(1.30 \mathrm{mg} / \mathrm{g})>$ aqueous extract $(0.51 \mathrm{mg} / \mathrm{g})>$ petroleum ether extract $(0.18 \mathrm{mg} / \mathrm{g})$, the maximum myricetin contents were present in methanol extract $(6.67 \mathrm{mg} / \mathrm{g})$ but in latex no myricetin was found, it may be below the detection

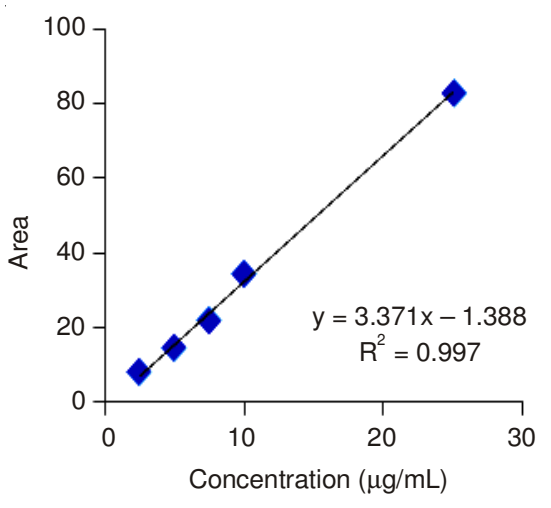

(A)

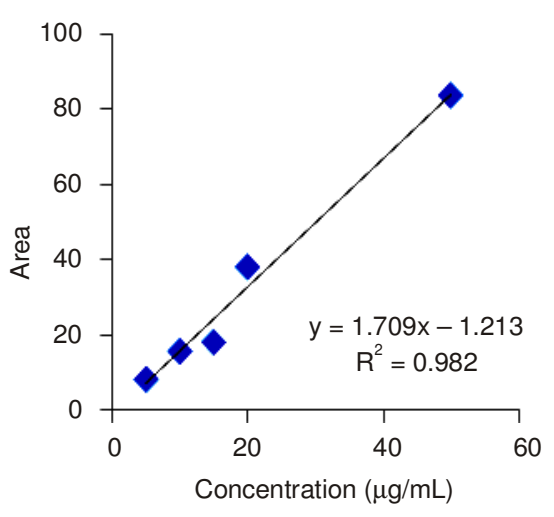

(B)

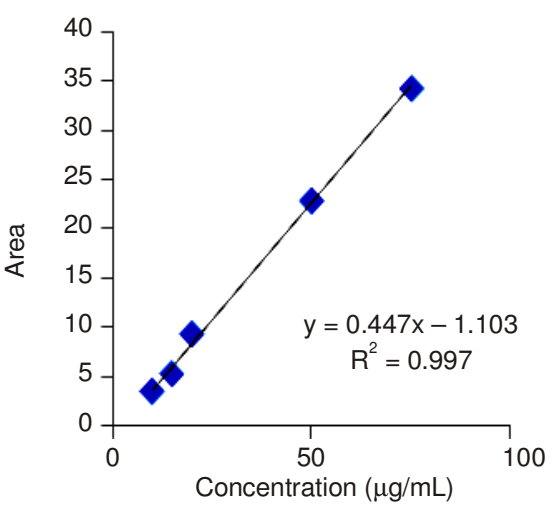

(C)

Fig. 1. Calibration curves of standard markers (mean $\pm \mathrm{SD} ; n=6$ ); $\mathrm{A}=$ Quercetin, $\mathrm{B}=$ Myricetin, $\mathrm{C}=$ Kaempferol

\begin{tabular}{|c|c|c|c|c|c|}
\hline \multicolumn{6}{|c|}{$\begin{array}{l}\text { TABLE-1 } \\
\text { LIMIT OF DETECTION (LOD) AND LIMIT OF QUANTIFICATION (LOQ) } \\
\text { OF QUERCETIN, MYRICETIN AND KAEMPFEROL }\end{array}$} \\
\hline Standards & Linear regression equation & $\mathrm{R}^{2}$ & Linear range $(\mu \mathrm{g} / \mathrm{mL})$ & LOD $(\mu \mathrm{g} / \mathrm{mL})$ & $\mathrm{LOQ}(\mu \mathrm{g} / \mathrm{mL})$ \\
\hline Quercetin & $Y=3.3716 X-1.388$ & 0.997 & $2.5-25.00$ & 0.04 & 0.15 \\
\hline Myricetin & $Y=1.7092 X-1.2132$ & 0.982 & $5.00-50.00$ & 0.04 & 0.15 \\
\hline Kaempferol & $Y=0.4748 x-1.1039$ & 0.998 & $10.00-75.00$ & 0.54 & 1.81 \\
\hline
\end{tabular}

TABLE-2

INTER-DAY AND INTRA-DAY ACCURACY AND PRECISION OF QUERCETIN, MYRICETIN AND KAEMPFEROL

\begin{tabular}{|c|c|c|c|c|c|c|c|c|}
\hline \multirow{2}{*}{$\begin{array}{c}\text { Nominal } \\
\text { concentration } \\
(\mu \mathrm{g} / \mathrm{mL})\end{array}$} & \multicolumn{4}{|c|}{ Intra-Day $(n=6)$} & \multicolumn{4}{|c|}{ Inter-Day $(n=6)$} \\
\hline & Value found & $\mathrm{SD}$ & Accuracy (\%) & Precision (\%) & Value found & SD & Accuracy (\%) & Precision (\%) \\
\hline \multicolumn{9}{|c|}{ Quercetin } \\
\hline 2.5 & 2.81 & 0.1 & 111.97 & 1.3 & 2.81 & 0.11 & 112.25 & 1.2 \\
\hline 5 & 4.74 & 0.03 & 94.68 & 0.19 & 4.74 & 0.04 & 94.79 & 0.21 \\
\hline 7.5 & 6.89 & 0.02 & 91.79 & 0.08 & 6.89 & 0.04 & 91.84 & 0.09 \\
\hline 10 & 10.6 & 0.01 & 105.99 & 0.04 & 10.6 & 0.03 & 106 & 0.06 \\
\hline 25 & 24.95 & 0.02 & 99.86 & 0.02 & 24.95 & 0.05 & 99.82 & 0.04 \\
\hline \multicolumn{9}{|c|}{ Myricetin } \\
\hline 5 & 5.66 & 0.04 & 113.17 & 0.53 & 5.68 & 0.11 & 113.65 & 0.55 \\
\hline 10 & 10.01 & 0.01 & 100.08 & 0.08 & 10.03 & 0.04 & 100.28 & 0.06 \\
\hline 15 & 11.43 & 0.01 & 76.19 & 0.04 & 11.45 & 0.04 & 76.33 & 0.07 \\
\hline 20 & 23.12 & 0.01 & 115.58 & 0.02 & 23.13 & 0.03 & 115.64 & 0.04 \\
\hline 50 & 49.75 & 0.00 & 99.49 & 0.01 & 49.74 & 0.05 & 99.48 & 0.03 \\
\hline \multicolumn{9}{|c|}{ Kaempferol } \\
\hline 10 & 9.81 & 0.03 & 98.05 & 0.85 & 10.29 & 0.05 & 102.93 & 0.95 \\
\hline 15 & 14.30 & 0.01 & 95.32 & 0.17 & 14.80 & 0.03 & 98.67 & 0.21 \\
\hline 20 & 19.55 & 0.01 & 97.73 & 0.09 & 20.06 & 0.02 & 100.32 & 0.11 \\
\hline 50 & 49.01 & 0.03 & 98.02 & 0.11 & 49.62 & 0.06 & 99.24 & 0.1 \\
\hline 75 & 74.56 & 0.01 & 99.41 & 0.03 & 75.25 & 0.02 & 100.33 & 0.06 \\
\hline
\end{tabular}




\begin{tabular}{|c|c|c|c|c|}
\hline \multicolumn{5}{|c|}{$\begin{array}{c}\text { TABLE-3 } \\
\text { QUALITY CONTROL SAMPLES }\end{array}$} \\
\hline \multirow{2}{*}{ Standard markers $(\mathrm{n}=3)$} & \multirow{2}{*}{ Nominal concentration $(\mu \mathrm{g} / \mathrm{mL})$} & Concentration found & \multirow{2}{*}{ Accuracy $(\%)$} & \multirow{2}{*}{ Precision $(\%)$} \\
\hline & & $(\mu \mathrm{g} / \mathrm{mL} ;$ mean $\pm \mathrm{SD})$ & & \\
\hline \multirow{3}{*}{ Quercetin } & 2.5 & $2.5 \pm 0.08$ & 99.84 & 1.15 \\
\hline & 7.5 & $7.51 \pm 0.04$ & 100.07 & 0.12 \\
\hline & 25 & $25.01 \pm 0.03$ & 100.05 & 0.05 \\
\hline \multirow{3}{*}{ Myricetin } & 2.5 & $2.48 \pm 0.03$ & 99.3 & 0.87 \\
\hline & 7.5 & $7.5 \pm 0.02$ & 100 & 0.04 \\
\hline & 25 & $25 \pm 0.01$ & 100 & 0.01 \\
\hline \multirow{3}{*}{ Kaempferol } & 10 & $9.75 \pm 0.04$ & 97.53 & 0.71 \\
\hline & 20 & $19.54 \pm 0.03$ & 97.7 & 0.07 \\
\hline & 75 & $74.57 \pm 0.06$ & 99.42 & 0.03 \\
\hline
\end{tabular}

limit. While kaempferol contents were quantified only in petroleum ether and chloroform extracts, in rest of samples it was below detection limit (Table-4). Representative chromatograms were given in Fig. 2.

\begin{tabular}{cccc} 
TABLE-4 \\
$\begin{array}{c}\text { QUANTIFICATION OF QUERCETIN, MYRICETIN AND } \\
\text { KAEMPFEROL IN VARIOUS EXTRACTS AND } \\
\text { LATEX OF Euphorbia helioscopia }\end{array}$ \\
\hline Samples & $\begin{array}{c}\text { Quercetin } \\
(\mathrm{mg} / \mathrm{g})\end{array}$ & $\begin{array}{c}\text { Myricetin } \\
(\mathrm{mg} / \mathrm{g})\end{array}$ & $\begin{array}{c}\text { Kaempferol } \\
(\mathrm{mg} / \mathrm{g})\end{array}$ \\
\hline (extracts) & 0.51 & 0.49 & 0 \\
Aqueous & 5.60 & 1.17 & 0 \\
Ethanol & 0.18 & 0.49 & 0.55 \\
Petroleum ether & 1.30 & 3.35 & 1.83 \\
Chloroform & 5.32 & 6.67 & 0 \\
Methanol & 1.40 & 0.00 & 0 \\
Latex & & &
\end{tabular}
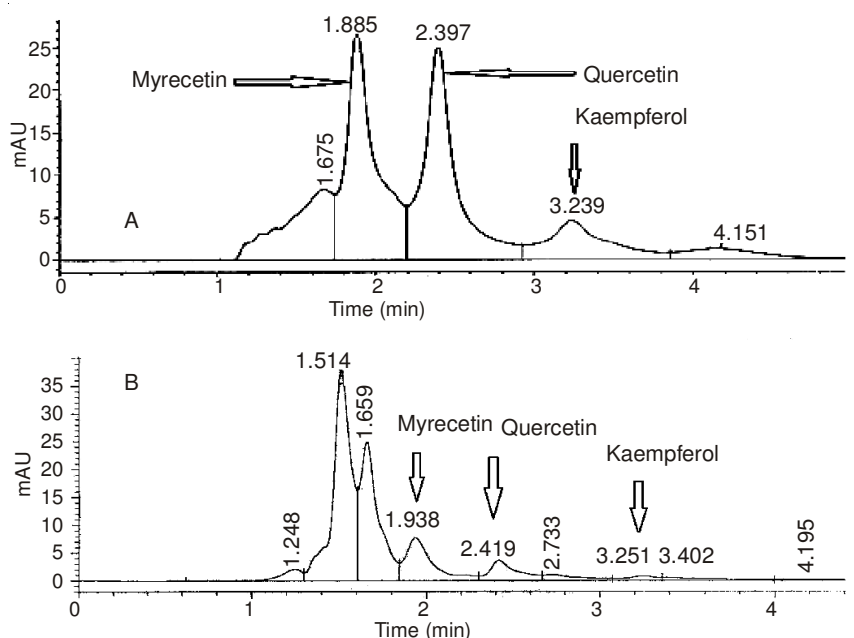

Fig. 2. Chromatograms of A: Mixed standard markers (quercetin, myricetin and kaempferol) and B: Chloroform extract of Euphorbia helioscopia

\section{ACKNOWLEDGEMENTS}

The authors acknowledge the financial support provided by Higher Education Commission of Pakistan.

\section{REFERENCES}

1. A.D. Kinghorn and F.J. Evans, Planta Med., 28, 325 (1975)

2. G.L. Webster, Ann. Mo. Bot. Gard., 81, 3 (1994).

3. A.K. Nadkarni, Indian Materia Medica, Popular Parkashan, Bombay, India, edn. 3, p. 523 (2002).

4. H. Panda, Handbook on Medicinal Herbs with Uses, p. 512 (2004); Retrieved from http:/books.google.com

5. N.A. Al Zanbagi, A.E.A. Banaja and J. Barrett, J. Ethnopharmacol., 70, 119 (2000).

6. K.H. Park, K. Dongsoo, L. Seungho, I. Jung, H.K. Kyung and C.H. Lee, J. Microbiol. Biotechnol., 11, 138 (2001).

7. A. Barla, H. Birman, S. Kultur and S. Oksuz, Turk. J. Chem., 30, 325 (2006).

8. M. Ramezani, J. Behravan, M. Arab and S.A. Farzad, J. Biol. Sci., 8, 809 (2008).

9. M. Uzair, B.A. Loothar and B.A. Choudhary, Pak. J. Pharm. Sci., 22, 184 (2009).

10. M. Nikolova, L. Evstatieva and T.D. Nguyen, Botanica Serbica, 35, 43 (2011).

11. M.L. Ben-Mohamed, A. Jelassi, I. Hassen and M.S.O.A. Ould, Int. Food Res. J., 19, 1125 (2012).

12. A.K. Farhat, U.R.K. Muneeb, M.M.S. Syed, Z. Mohammad and M.H.S. Syed, Middle-East J. Sci. Res., 9, 200 (2011).

13. Z.Y. Wang, P.H. Liu, Y.C. Zhang, L.Q. Guo, Z.X. Li and X.F. Shi, Anat. Rec., 295, 223 (2012).

14. M. Nazir, W. Ahmad and W. Kreiser, Pak. J. Sci. Ind. Res., 41, 6 (1998).

15. S. Yamamura, S. Kosemura, S. Ohba, M. Ito and Y. Saito, Tetrahedron Lett., 22, 5315 (1981).

16. S. Yamamura, Y. Shizuri, S. Kosemura, J. Ohtsuka, T. Tayama, S. Ohba, M. Ito, Y. Saito and Y. Terada, Phytochemistry, 28, 3421 (1989).

17. S. Kosemura, Y. Shizuri and S. Yamamura, Bull. Chem. Soc. Jpn., 58, 3112 (1985).

18. Y. Shizuri, S. Kosemura, J. Ohtsuka, Y. Terada, S. Yamamura, S. Ohba, M. Ito and Y. Saito, Tetrahedron Lett., 25, 1155 (1984).

19. A. Kawase and N. Kutani, Agric. Biol. Chem., 32, 121 (1968).

20. Y. Chen, Z. Tang, F. Jiang, X. Zhang and A. Lao, Acta Pharmacol. Sin., 14, 91 (1979).

21. W. Zhang and Y.W. Guo, Chem. Pharm. Bull. (Tokyo), 54, 1037 (2006).

22. C. Liu, M. Sun, L. Wang, G. Wang, G. Chen, C. Liu and P. Liu, Chin. Med., 3, 1 (2008).

23. U. Saleem, K.D. Hussain, M. Ahmad, N.I. Bukhari, A. Malik and B. Ahmad, Pak. J. Pharm. Sci., 27, 577 (2014).

24. I.N. Papadoyannis and V.F. Samanidou, J. Liq. Chromatogr. Rel. Technol., 27, 753 (2005).

25. United States Pharmacopoeia-National Formulary, United States Pharmacopoeial Convention, Rockville, edn. 26, p. 1767 (2003).

26. L. Huber, Intl. Lab., 9, 8 (1995). 